ARS

ano 17 Ensaio Visual

ก. 37

\title{
Lucas Eskinazi
}

Barcelona, 2019

Lucas Eskinazi é artista e pesquisador. Formado em letras e cinema, é mestre pelo programa de poéticas visuais na Universidade de São Paulo. 
barcelona,

2019 


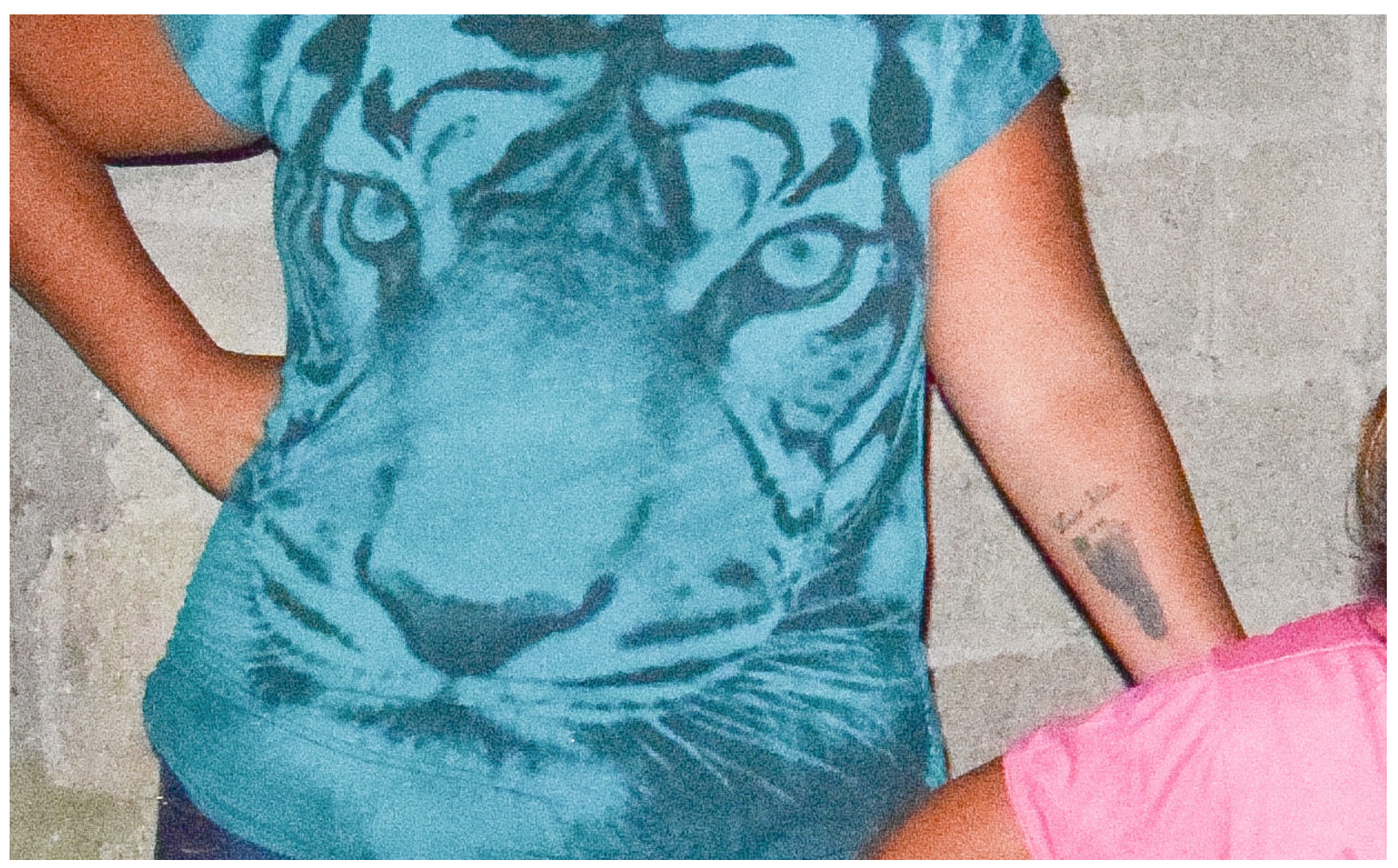




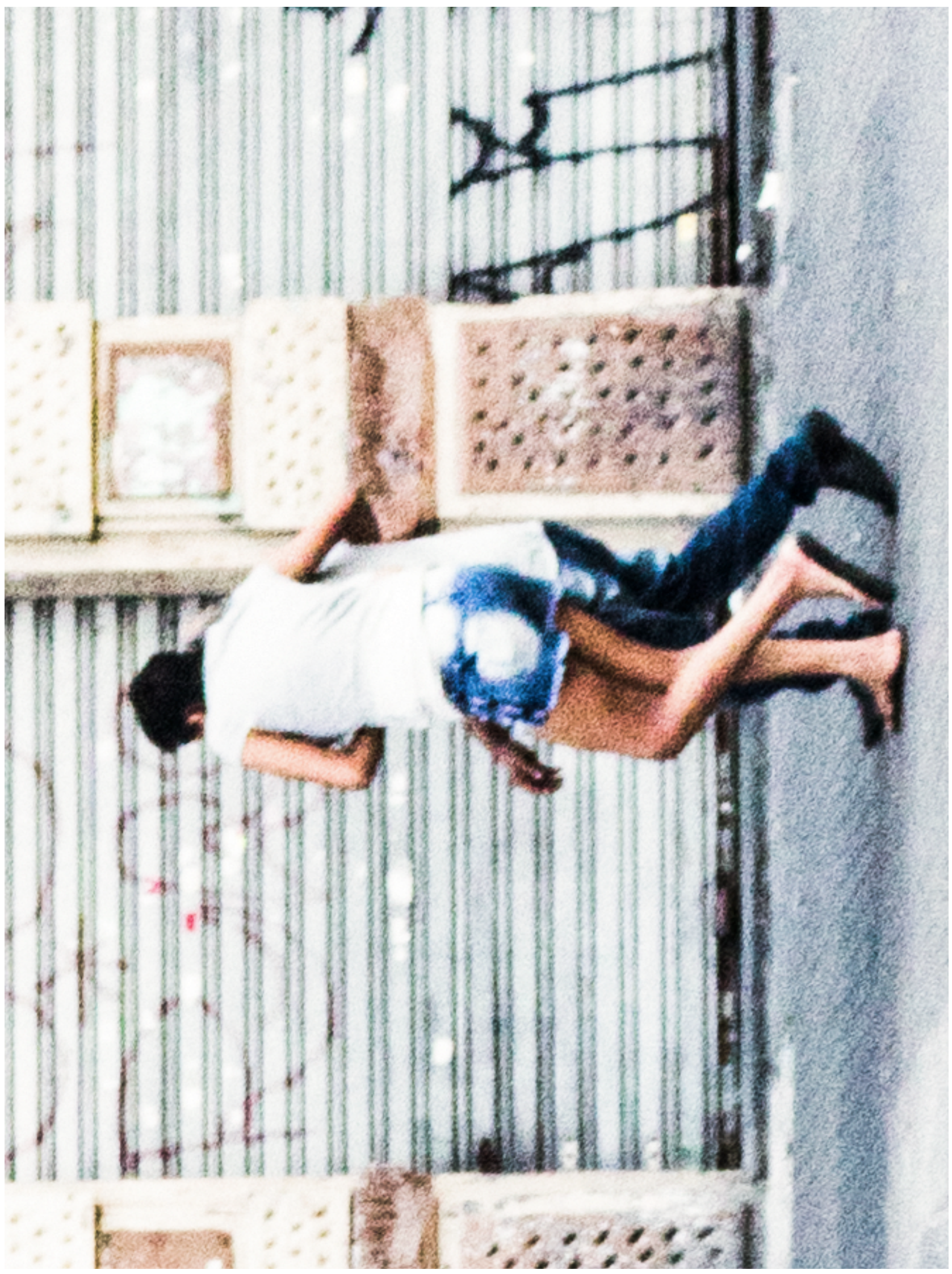




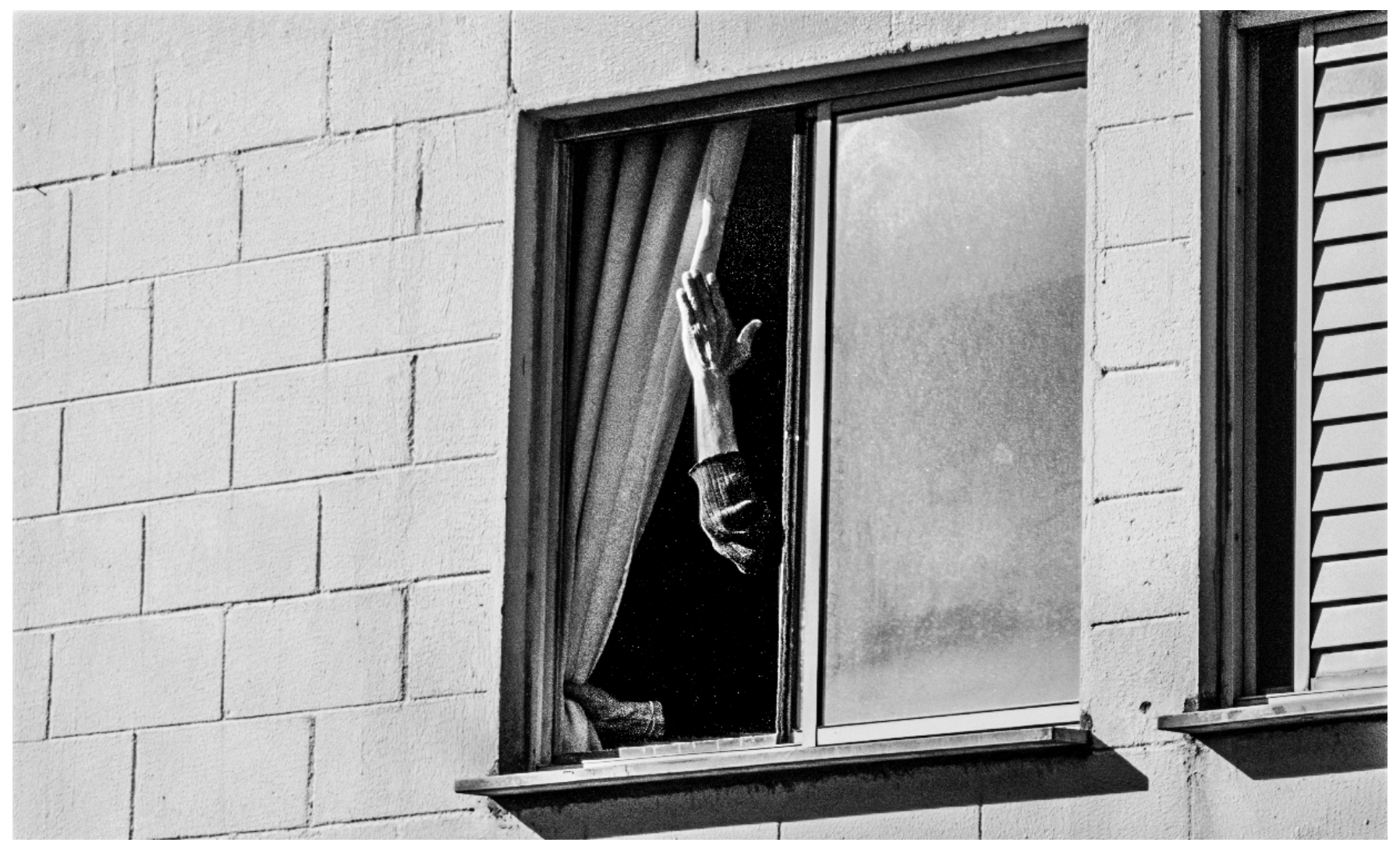



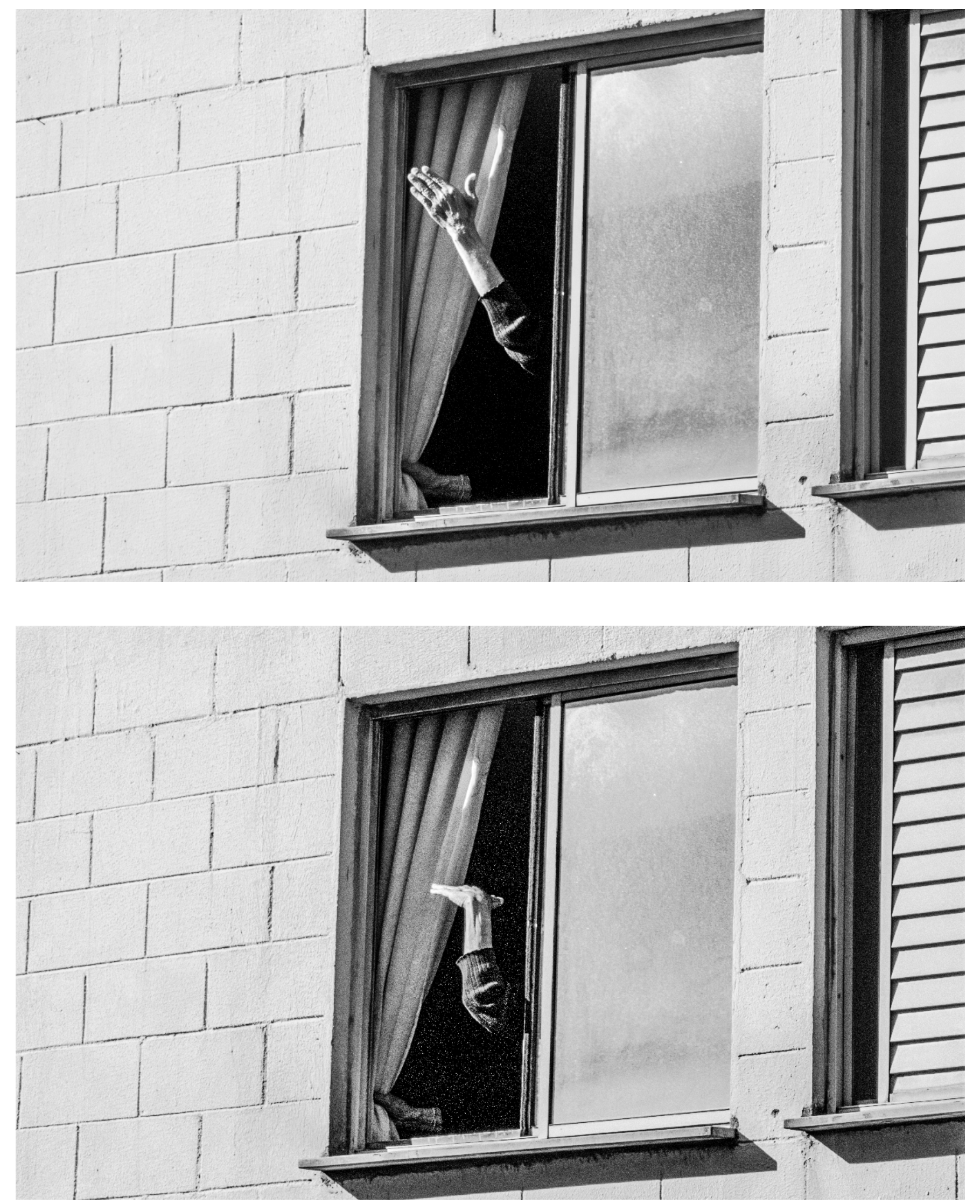


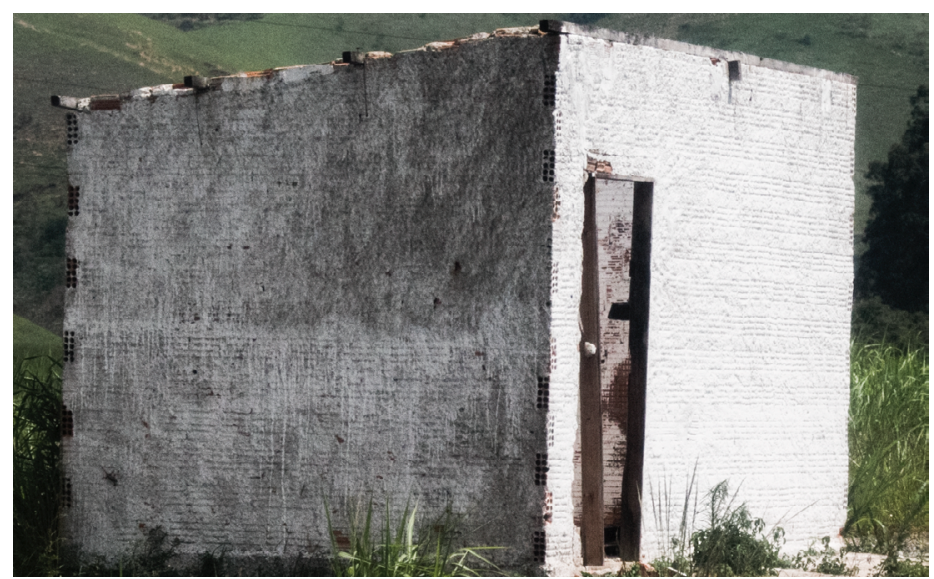




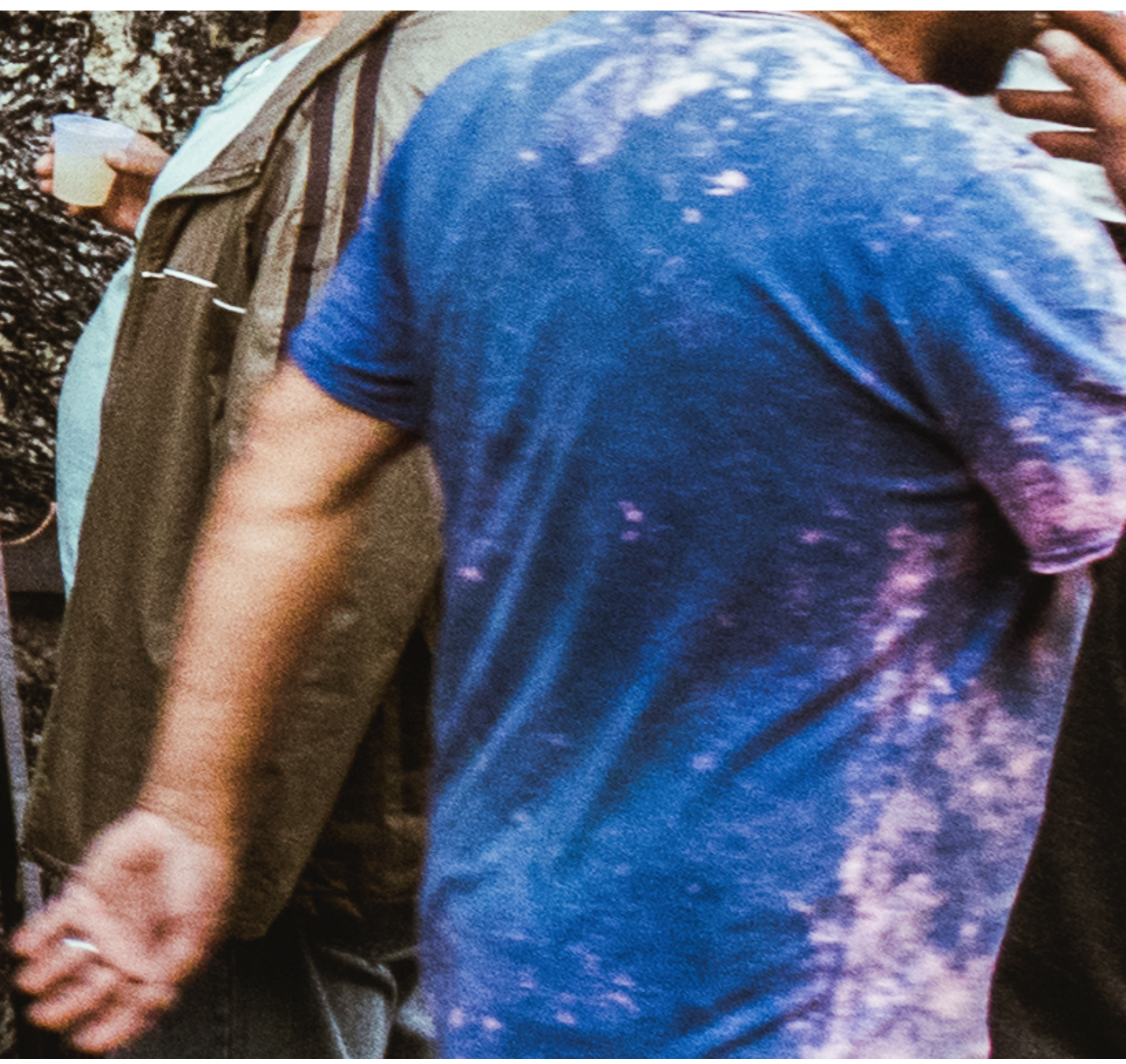



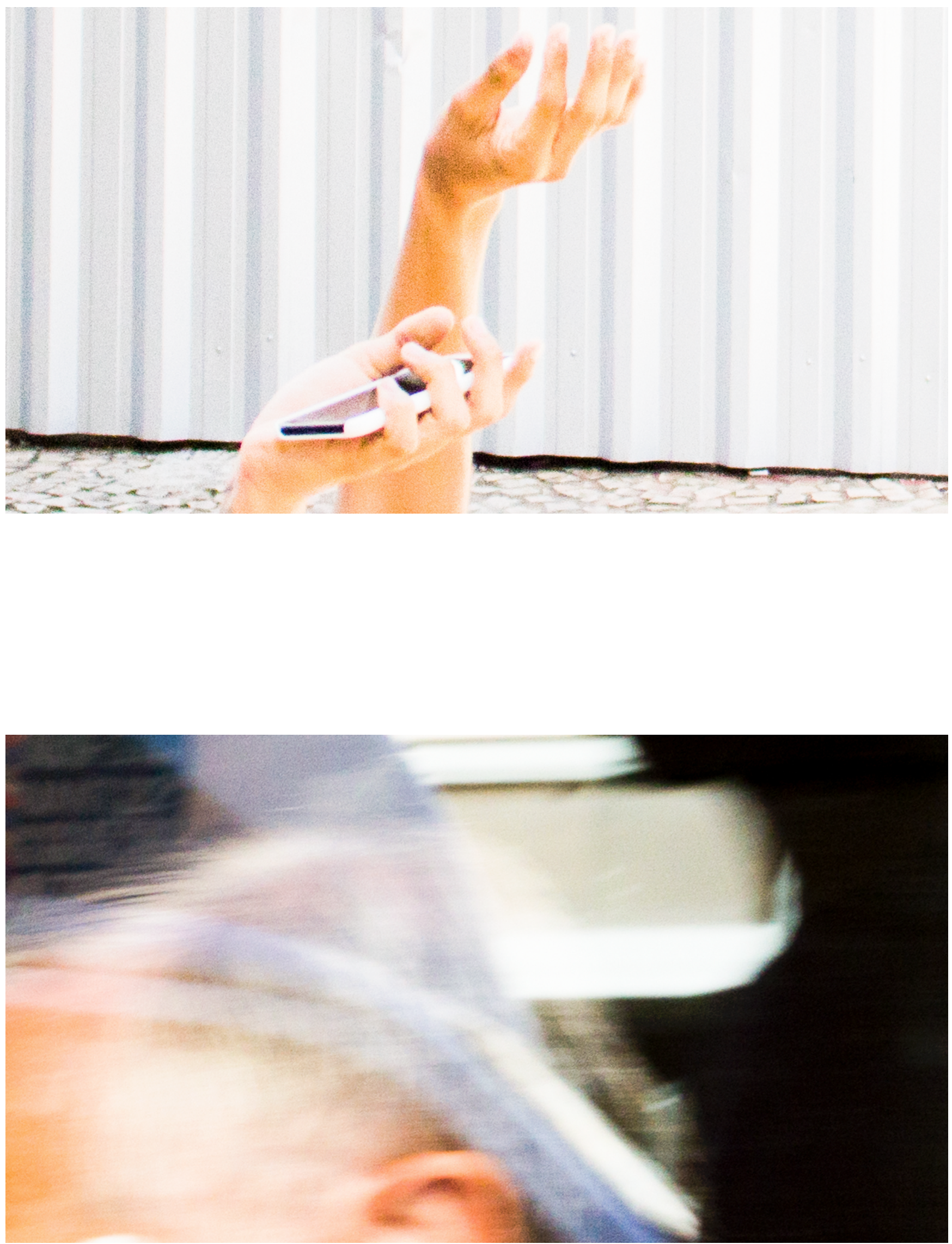


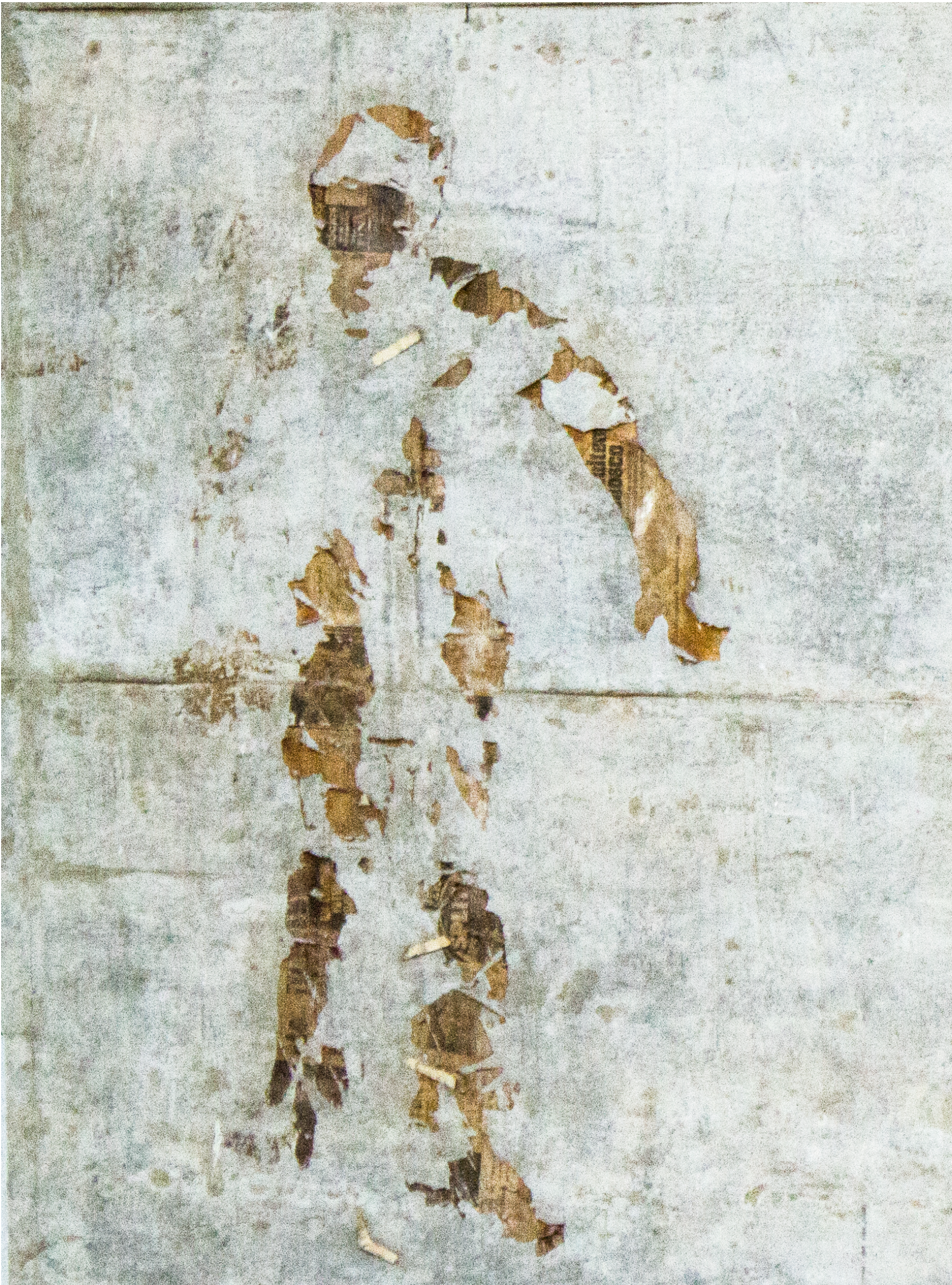




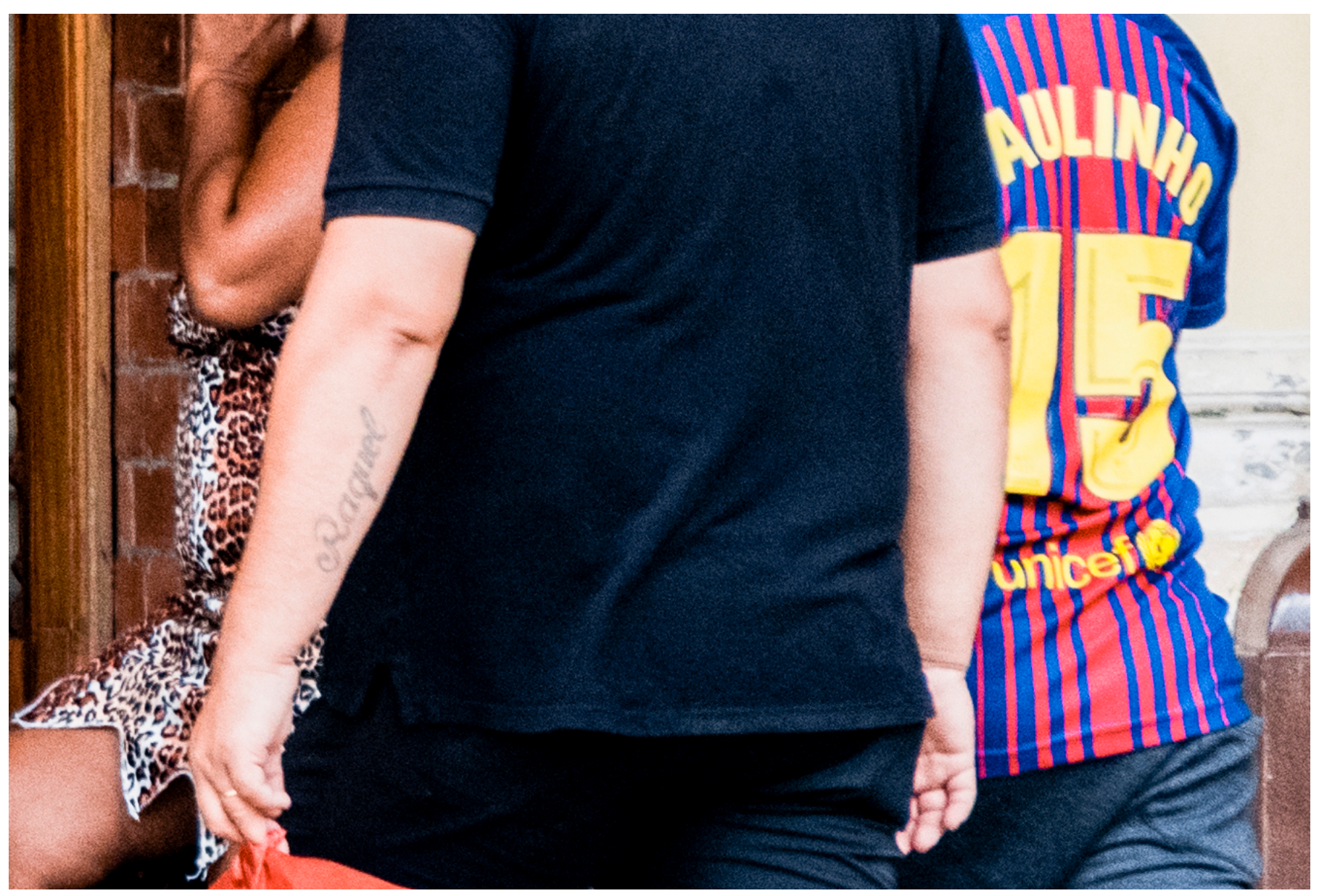




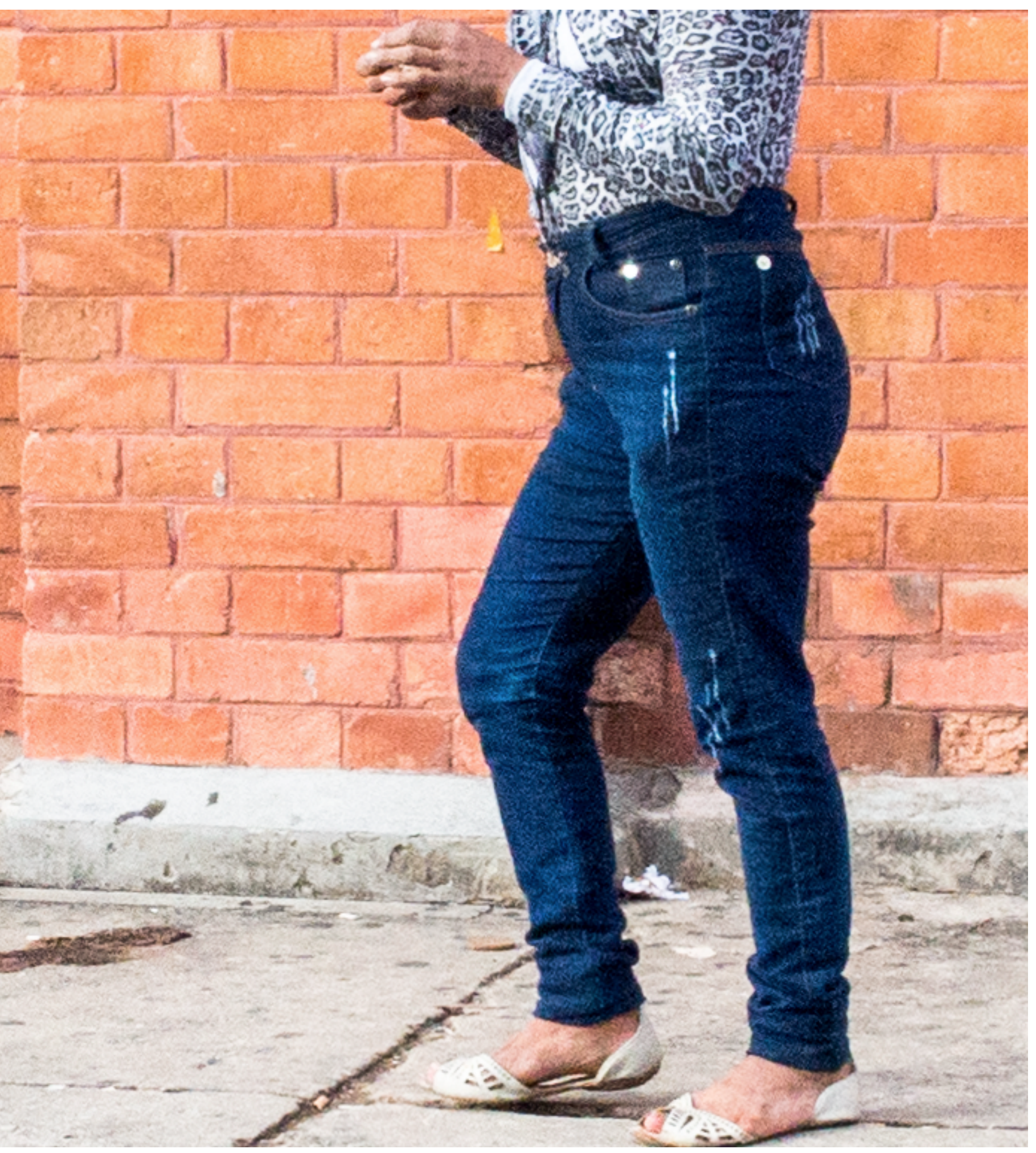


ti 


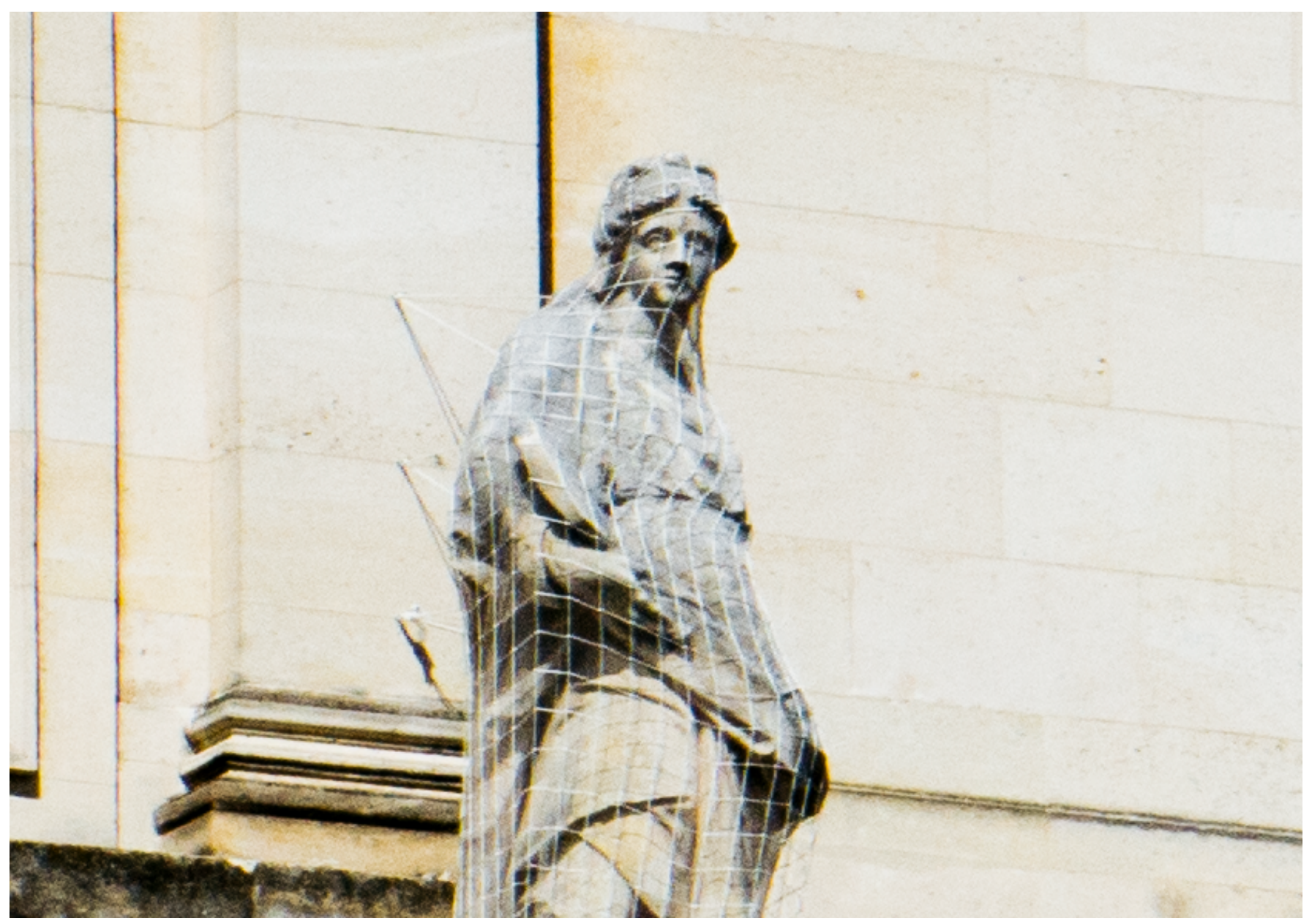




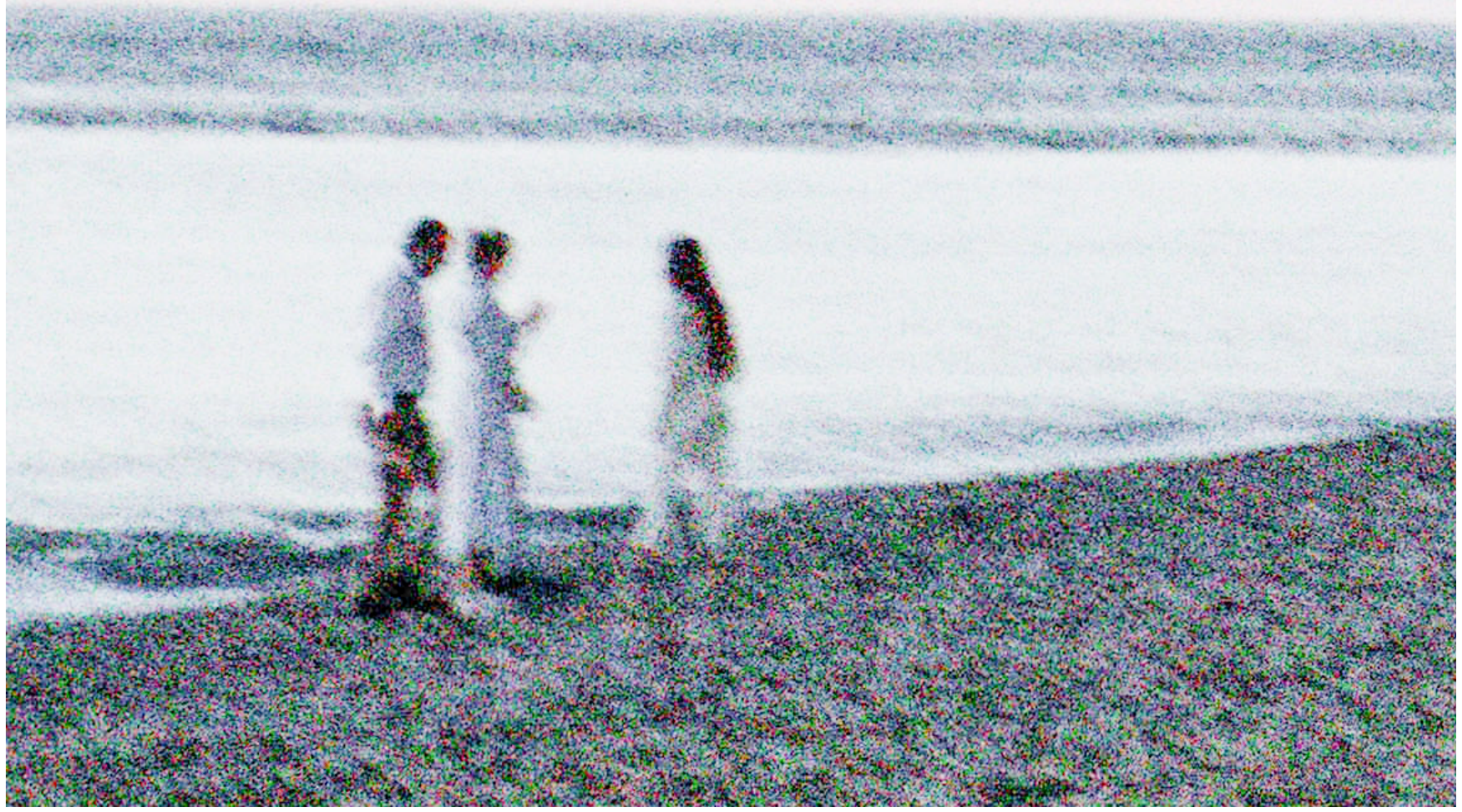




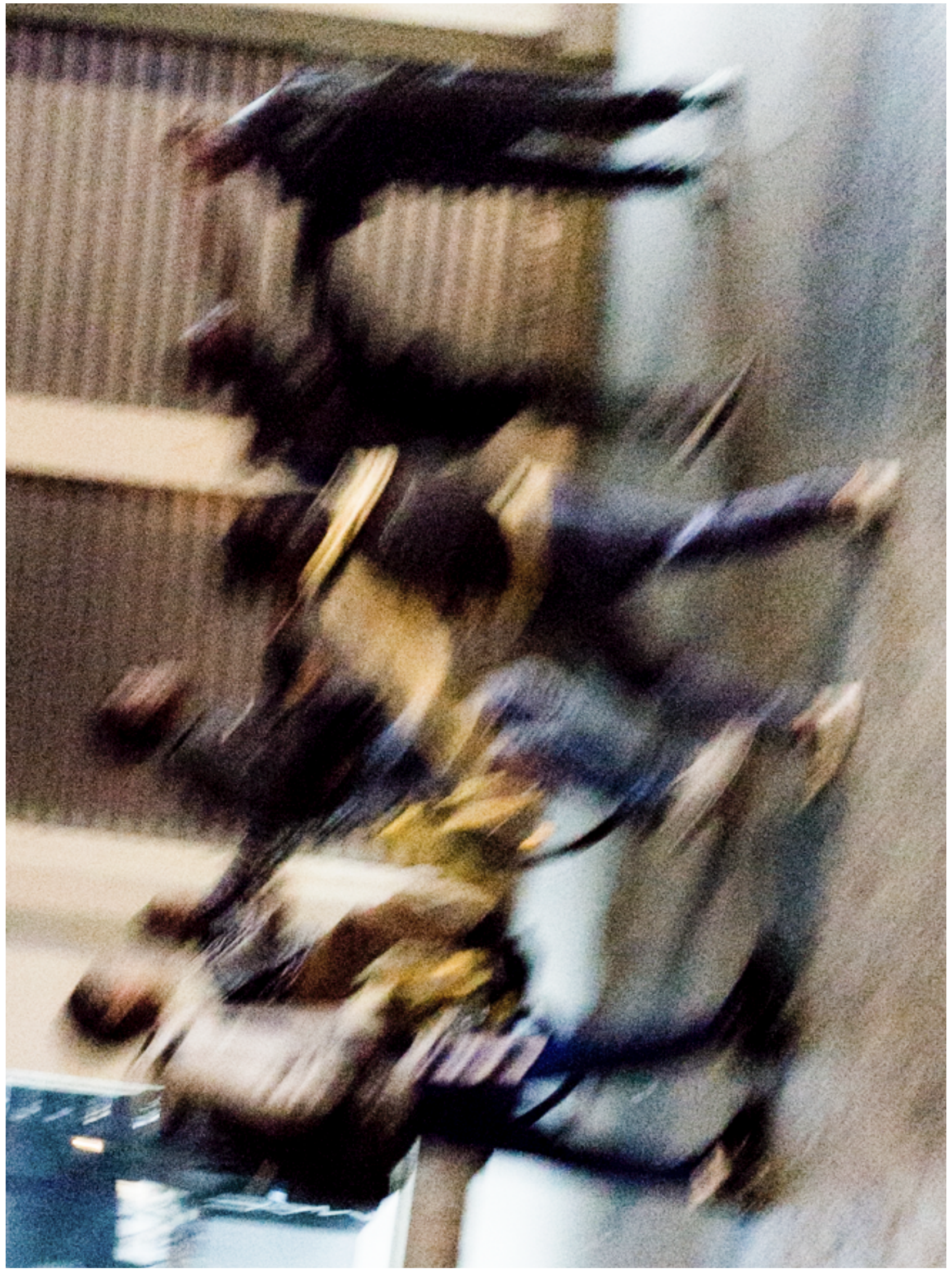


